\title{
INFLUENCE OF ATMOSPHERIC CORROSION ON THE SERVICE LIFE OF STEEL SHEETS
}

The paper analyses the influence of the duration of atmospheric corrosion on basic mechanical and fatigue properties of steel sheet 2.16-4.46 mm thick, made of low-carbon steel with higher atmospheric corrosion resistance. A decrease of mechanical properties as a function of the exposure time is mainly due to a weight loss and the fatigue limit decrease under flat bending is due to increased surface roughness weathering steel too. The fatigue limit is a crucial characteristic for the service life of products, since after 5 years of exposure it decreased by $36 \%$, while the ultimate tensile strength decreased by as little as $8 \%$.

Key words: Low-carbon steel, corrosion resistance, surface roughness, mechanical properties, fatigue limit.

\section{Introduction}

Most metal structures and equipment (80\%) work under atmospheric corrosion conditions. The atmospheric corrosion rate depends to a great extent on the presence of gaseous or dissolved solid impurities, mainly $\mathrm{SO}_{2}, \mathrm{H}_{2} \mathrm{~S}, \mathrm{HCl}$, chlorides, etc. The chemical composition of steel also plays a significant role in assessing the atmospheric corrosion processes [1]. Therefore, low-carbon steels with increased atmospheric corrosion resistance of COR-TEN type were developed, which are currently manufactured under various trademarks. These steels are generally characterized as complex low-alloyed steels of $\mathrm{Cu}-\mathrm{Cr}$-Ni-P chemical concept, with an ability to create, under certain atmospheric conditions, a continuous and very adhesive layer of corrosion products on their surface. This layer effectively slows down the further corrosion process and has an aesthetic appearance $[2,3,4]$.

As a result of corrosion, degradation of chemical properties of steels takes place. Under atmospheric corrosion conditions, degradation of mechanical properties is mainly caused by a weight loss (thickness) and a change of the surface relief (increased roughness). Literature shows that these changes are the most intensive at the beginning of the service life and with the exposure time the degradation intensity decreases and in steels with increased corrosion resistance it approaches to zero $[3,5,6]$. The loss of weight mainly decreases the calculated values of strength properties and the change of roughness mainly decreases plastic properties, but particularly the fatigue life $[6,7,8,9,10]$. The fatigue life of surface-damaged products is very susceptible to the method of variable loading [9]. For flat products, flat bending is the most frequent method of variable loading, where surface unevenness plays an important role, where fatigue failure is initiated.

The aim of the paper is to analyze the influence of atmospheric corrosion on basic mechanical properties and fatigue char- acteristics of hot rolled sheets made of low-carbon steel with higher atmospheric corrosion resistance.

\section{Experiments and their analysis}

Experiments were made on steel strips $2.16-4.46 \mathrm{~mm}$ thick, made of low-carbon steel with increased atmospheric corrosion resistance KONOX $345 \mathrm{~T}$. Their orientation chemical composition is: $C_{\max }=0.12 \%, M n=0.20-0.44 \%, S i=0.25-0.55 \%, P=$ $=0.07-0.15 \%, S_{\max }=0.015 \%, A l_{\min }=0.02 \%, C u=0.25-0.60 \%$, $\mathrm{Cr}=0.50-1.2 \%, N i_{\max }=0.65 \%$. The microstructure of tested sheets is fine-grained, ferritic-pearlitic.

For experiments, tensile and fatigue test bars were made of the tested steel strips (Fig. 1). Some of these test bars were exposed to atmospheric corrosion for a period up to 5 years. On such prepared test bars, the surface roughness was measured and the metallographic analysis of the surface layer was made. The influence of the exposure time on mechanical and fatigue properties was investigated using tensile tests and fatigue tests under flat bending $(R=-1)$ at the frequency of $35 \mathrm{~Hz}$. The fatigue limit was determined for the number of cycles to failure $10^{7}$.

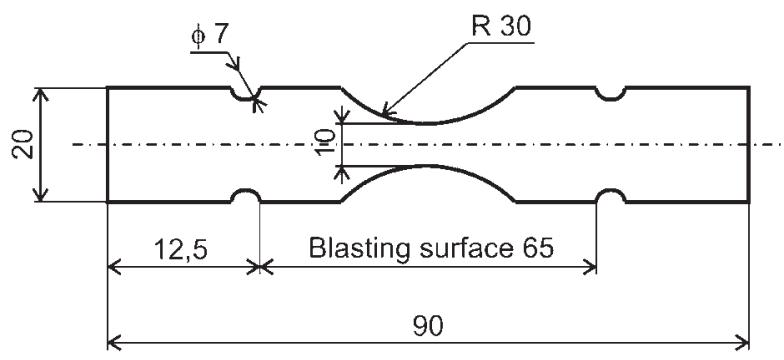

Fig. 1 Test bars for fatigue tests under flat bending

\footnotetext{
* Marián Buršák, Ján Michel’

Faculty of Metallurgy, Technical University of Kosice, Letná 9, 04200 Košice, Slovakia,E-mail: Marian.Bursak@tuke.sk
} 


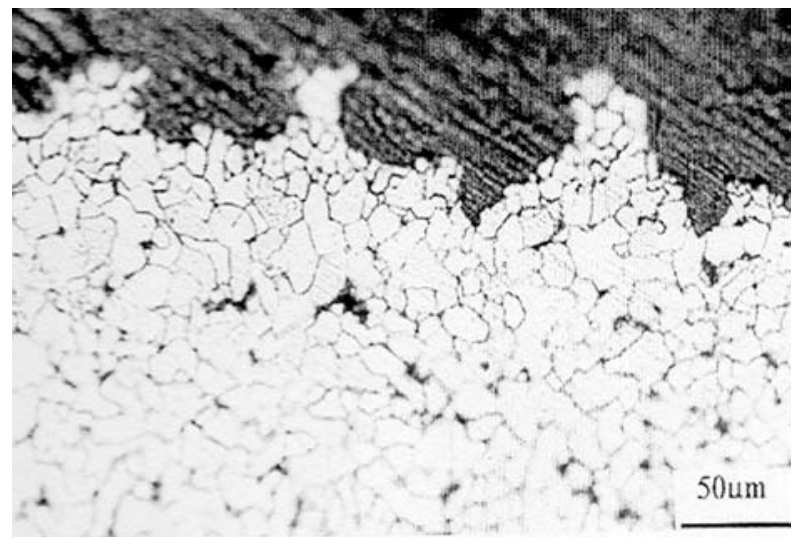

Fig. 2 Microstructure of a surface layer after 5 years exposure to atmospheric corrosion

As a result of atmospheric corrosion, a loss in weight and a change in the surface morphology take place. Figure 2 documents the surface morphology after 5 years of exposure to atmospheric corrosion and Fig. 3 documents the relationship between the change of surface roughness and the time of exposure of tested sheets to atmospheric corrosion, represented by the mean arithmetic deviation of the profile $R_{a}$ and the highest height of the profile $R_{y}$, A significant change of the profile takes place within the first 2 years of exposure and then this change is mitigated, even saturation takes place. The above-mentioned analysis also resulted in the program of mechanical tests. Basic mechanical and fatigue properties were investigated on the initial state, after 2 years and after 5 years of exposure to atmospheric corrosion.

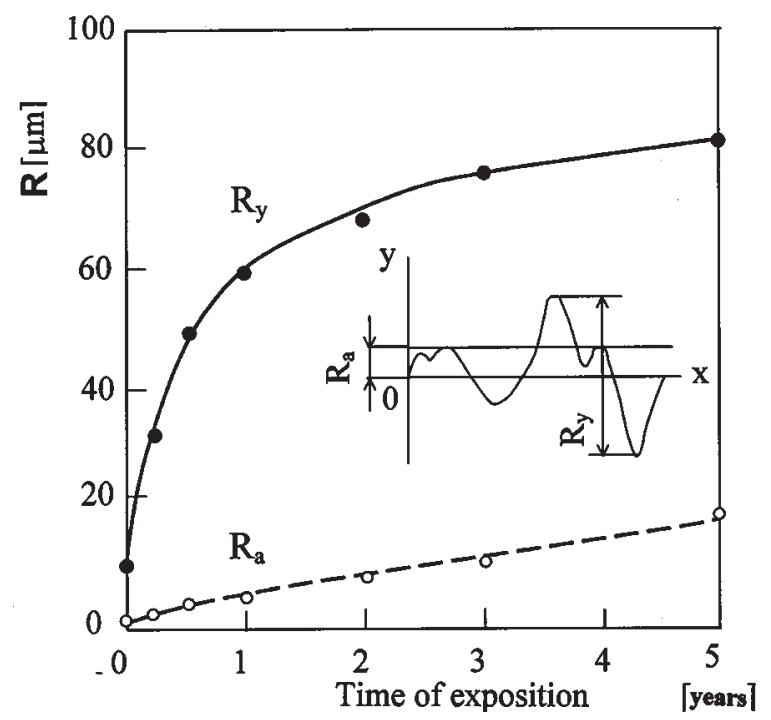

Fig. 3 Influence of the exposition time to atmospheric corrosion on surface roughness $R_{a}, R_{y}$

Figure 4 shows the relationships between the basic mechanical properties and the time of exposure to atmospheric corrosion, and Fig. 5 shows the relative decrease of the yield point $R_{e C O R} / \mathrm{R}_{\mathrm{e}}$ and the elongation $A_{80 \mathrm{COR}} / A_{80}$, respectively, after exposure. The

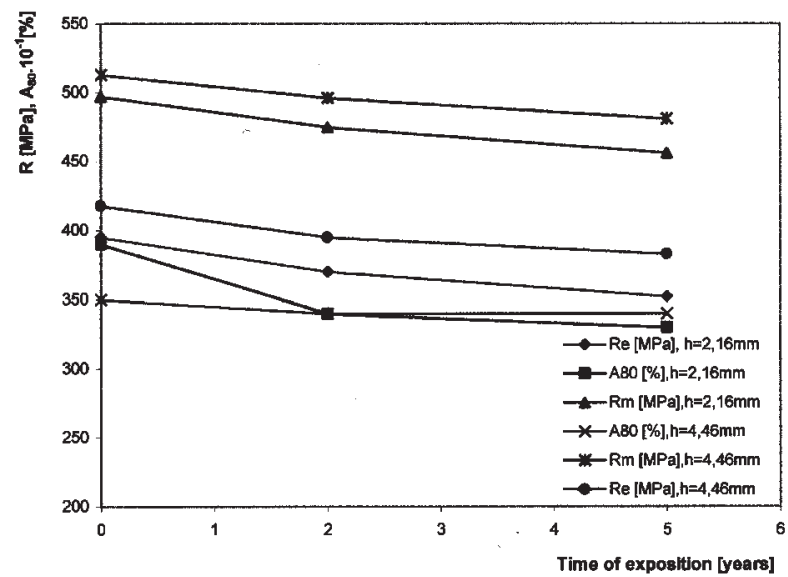

Fig. 4 Influence of the exposition time to atmospheric corrosion on basic mechanical properties

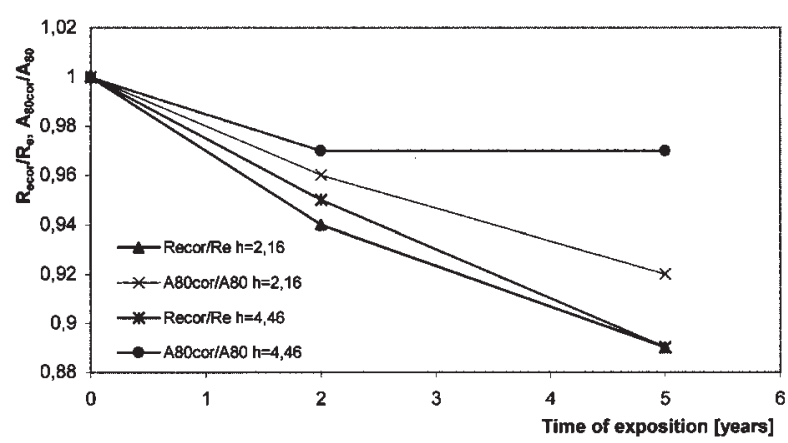

Fig. 5 Influence of the exposition time to atmospheric corrosion and the sheet thickness on the relative decrease of the yield point $R_{e \mathrm{COR}} / R_{e}$ and the elongation $A_{80 \mathrm{COR}} / A_{80}$

results show that the basic mechanical properties decrease significantly during the first 2 years and then their decrease is less significant. The decrease of mechanical properties of the tested steel due to atmospheric corrosion is also influenced by the sheet thick-

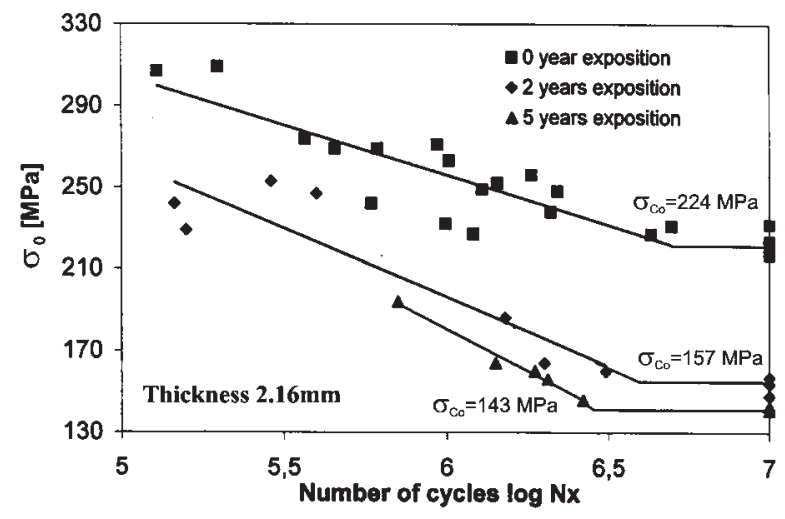

Fig. 6 Wöhler curves of the sheet $2.16 \mathrm{~mm}$ thick after $0-2$ and 5-year exposition to atmospheric corrosion 
ness; the less the thickness, the more significant the corrosion influence.

The results of the fatigue tests under flat bending at a symmetrical cycle are shown in Fig. 6 and Fig. 7. A decrease of the fatigue limit under flat bending after exposure to atmospheric corrosion when compared with the fatigue limit under bending of sheets in the initial state is shown in Fig. 8.

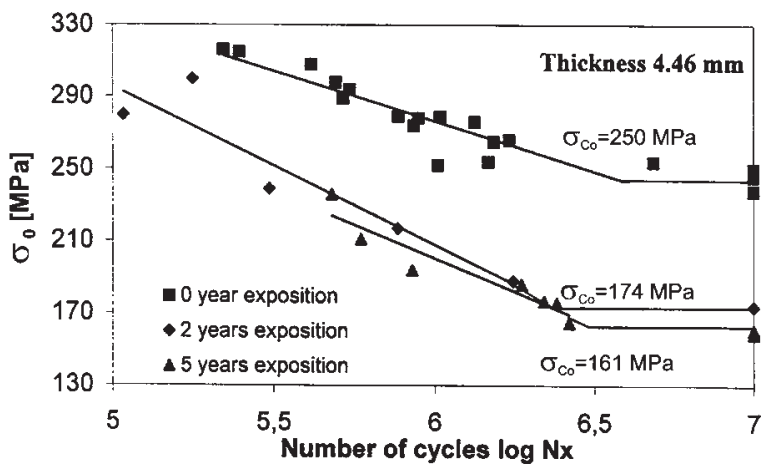

Fig. 7 Wöhler curves of the sheet $4.46 \mathrm{~mm}$ thick after $0-2$ and 5-year exposition to atmospheric corrosion

The analysis of the results of fatigue tests under bending at a symmetrical cycle indicates that within the first 2 years of exposure to atmospheric corrosion the fatigue limit of tested sheets significantly decreases, and when this exposure time is exceeded, the decrease of the fatigue limit is less significant or the fatigue limit is stabilized. The experiments show (Fig. 8) that the sheet thickness, in fact, does not influence the decrease of $\sigma_{C o}$ due to the time of exposure to atmospheric corrosion.

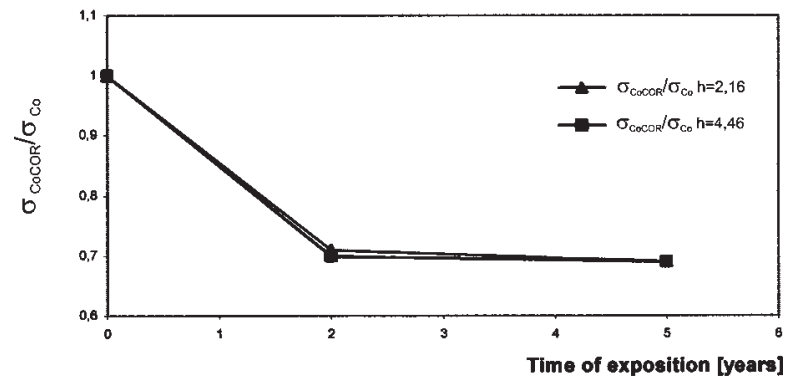

Fig. 8 Influence of the exposition time to atmospheric corrosion on the relative decrease of the fatigue limit under bending $\sigma_{\text {CoCOR }} / \sigma_{C o}$

The results of the influence of the atmospheric corrosion exposure time on the basic mechanical and fatigue properties of the tested sheets are in accordance with theoretical and practical knowledge. It is necessary to discuss factors that degrade the structural strength or the service life of flat products to a great extent Under static loading conditions, a weight loss (sheet thickness) is a crucial factor. Since this loss under atmospheric corrosion conditions, regardless of the sheet thickness, is constant, the intensity of decrease of the structural strength of thinner flat products will be higher (the thickness dependence is exponential); for the tested sheet $2.16 \mathrm{~mm}$ thick the decrease of $R_{m}$ due to atmospheric corrosion is $8 \%$ and for the sheet $4.46 \mathrm{~mm}$ thick this decrease is $6 \%$. From this point of view, the elimination of atmospheric corrosion by an addition to the thickness is effective. Considering the high plasticity of the tested sheets, but also other sheets intended for the manufacture of flat products, a decrease of the elongation due to increased surface roughness by atmospheric corrosion does not have a significant practical importance.

The experimental results and literary knowledge indicate that under variable loading conditions the surface roughness is a crucial factor of degradation of properties due to atmospheric corrosion, which significantly increases during the first two years of exposure and is not dependent on the sheet thickness. The decrease of the fatigue limit of the tested sheets after two years of exposure by $30 \%$, or after 5 years by $36 \%$, is significant. The loss in weight is practically negligible from the viewpoint of its effect on the fatigue limit. The work [6] shows that the loss in weight after 5 years of exposure participated in a decrease of the fatigue limit by as little as $4 \%$.

It results from the above-mentioned that the solution of the influence of atmospheric corrosion on the fatigue life by an addition to the sheet thickness is of a little effect. The solution consists in reducing the surface roughness of sheet (flat product), particularly its Ry value. From the viewpoint of the material design of a product, this means that we should choose a steel sheet grade that guarantees the formation of a uniform, continuous layer of corrosion products. Low-carbon steels with increased atmospheric corrosion resistance, and hence the tested steel KONOX 345 T, meet this condition to a certain degree. As a result of their complex alloying, under atmospheric corrosion conditions within two-three years a protective layer is formed, which, in fact, stops the corrosion process. The work [6] compares the degradation of the tensile fatigue limit at the max-to-zero cycle $(R=0)$ of steel with increased resistance to atmospheric corrosion 15127.1 and unalloyed steel 11523.1. After 5 years of exposure, the fatigue limit for the number of cycles $10^{7}$ decreased by $34 \%$ for steel 15127.1 and by $40 \%$ for steel 11523.1. Under flat bending conditions, this difference is even higher.

\section{Conclusion}

The paper analyses the influence of the time of exposure to atmospheric corrosion (2-5 years) on the basic mechanical and fatigue properties of complex low-alloyed steel with increased resistance to atmospheric corrosion KONOX $345 \mathrm{~T}$. The analysis of experimental results and literary knowledge gave the following conclusions:

- The tested steel, besides advantageous mechanical properties, also meets the condition of increased resistance to atmospheric corrosion. After 2 years of exposure, the loss in weight and the increase of surface roughness of sheet are stabilized, even stopped. - The decrease of mechanical properties $\left(R_{e}, R_{m}\right)$ as a function of the time of exposure to atmospheric corrosion is identical to 
the course of the loss in weight; hence, the loss in weight is a crucial degradation factor. Since this loss in weight is not dependent on the sheet thickness, the decrease of mechanical properties decreases with a growing thickness.

- The decrease of the fatigue limit under flat bending $(R=-1)$ as a function of the time of exposure to atmospheric corrosion is comparable with the course of the roughness profile height Ry. The roughness of the sheet surface is a crucial degradation factor, and hence the sheet thickness has only a slight effect on the decrease of the fatigue limit.

The decrease of the ultimate tensile strength due to atmospheric corrosion after five years of exposure was $8 \%$ for the sheet $2.16 \mathrm{~mm}$ thick and $6 \%$ for the sheet $4.46 \mathrm{~mm}$ thick, but the decrease of the fatigue limit under bending was as many as $36 \%$. Since flat products (e.g. parts of vehicles, containers, etc.) work under variable loading conditions, when calculating their service life the degradation of the fatigue limit will be a crucial factor. From this point of view, the use of steels with increased resistance to atmospheric corrosion for products with a long service life has high economic gains in terms of cost of surface protection and its renewal. Also, higher mechanical properties of these steels make it possible to reduce the product weight.

\section{References}

[1] KOCICH, J., TULEJA, S.: Corrosion of Metals (in Slovak), Alfa Bratislava, 1980

[2] KOLLÁR, J., ŠIMON, Á.: Steel Sheets (in Slovak), 25, 1, 1996, 19

[3] LAPČÍKOVÁ, E.: Metallurgical Letters (in Slovak), 19, 11, 1976, 815

[4] KOCICH, J., TULEJA, S.: Korózna ochrana kovov Corrosive protection of Metals (in Slovak), Alfa Bratislava, 1989

[5] ŠEVČÍKOVÁ, J.: METALLURGIST (in Czech), 33, 6, 1983, 228

[6] MICHEL, J., MIHALIKOVÁ, M.: Influence of corrosive enviroment on fatigue properties of steels,(in Slovak), In.: Letná škola únavy 2004, Zuberec-Roháče, sept. 2004, 62

[7] BURŠÁK, M. et al.: Influence of rolling conditions and atmospheric corrosion on mechanical and fatigue properties of KONOX grade steel (in Slovak), In.: Valcovanie plechov za tepla, Stará Lesná, okt. 2000, P34-1

[8] MIHALÍKOVÁ, M., KOVALOVÁ, K., MICHEL, J.: Material Engineering (in Slovak), 11, 3, 2004, 13

[9] KOVALOVÁ, K., MICHEL, J.: Acta Mechanica Slovaca, 8, 2004, 3, 113

[10] MAMUZIČ, I.: Metallurgy (in English), 44, 2005, 4, 305 